\title{
Novel application of Hemospray to achieve hemostasis in post-variceal banding esophageal ulcers that are actively bleeding
}

Esophageal variceal band ligation (EVL) has been described as the best treatment option for esophageal variceal bleeding (EVB) [1]. Following EVL, a local ulcer is commonly found that heals within 2-3 weeks, allowing the development of fibrosis in the submucosa. If the rubber band detaches prematurely, before variceal thrombosis has occurred, massive bleeding may occur at the site of the detached band [2]. This complication is rare but difficult to manage and is associated with mortality of up to $52 \%$ [3-5]. Management is based on endoscopic injection of cyanoacrylate when available, or balloon tamponade as a bridge to a rescue transjugular intrahepatic portosystemic shunt (TIPS) procedure [5].

We report two cases of effective hemostasis using the novel hemostatic powder Hemospray (Cook Medical, WinstonSalem, North Carolina, USA). The nonabsorbable nanopowder is propelled to the area of bleeding by means of a carbon dioxide-containing cartridge with a positive outflow pressure; the noncontact technique allows the diffuse spray of the powder.

The first patient was a 56-year-old man who was admitted for hematemesis 13 days after endoscopy and EVL for EVB. Resuscitation was started and emergency endoscopy confirmed an actively bleeding post-banding esophageal ulcer (PBEU). Four injections of $1 \mathrm{ml}$ of cyanoacrylate into the bleeding ulcer were done, with temporary hemostasis. However during the next 12 hours, the patient experienced exteriorized blood loss and transfusion of 2 units of red blood cells was required. The second patient, a 53-yearold woman with hepatitis C cirrhosis, was transferred to our institution because of hematemesis 7 days after endoscopy and band ligation for acute variceal bleeding

\section{Video 1}

Use of hemostatic nanopowder for hemostasis of an actively bleeding post-variceal banding esophageal ulcer. in another institution. Endoscopy was performed in both patients confirming the actively bleeding PBEU. In each patient treatment with one kit of the hemostatic powder was applied until hemostasis was confirmed ( $\bullet$ Fig. 1, Video 1 ). Both patients were kept under surveillance for 24 hours. A follow-up endoscopy 24 hours later disclosed fibrinous deposits on the ulcer with no active bleeding. This technique may offer a convenient treatment method for controlling hemorrhage in this potentially life-threatening situation.

\section{Endoscopy_UCTN_Code_TTT_1AO_2AD}

\section{Competing interests: None}

\section{Mostafa Ibrahim ${ }^{1,2}$, Arnaud Lemmers ${ }^{1}$, Jacques Devière ${ }^{1}$}

${ }^{1}$ Department of Gastroenterology and Hepatopancreatology, Erasme Hospital, Université Libre de Bruxelles, Brussels, Belgium

2 Department of Gastroenterology and Hepatology, Theodor Bilharz Research Institute, Cairo, Egypt

\section{References}

1 Van Stiegmann G, Cambre T, Sun JH. A new endoscopic elastic band ligating device. Gastrointest Endosc 1986; 32: 230-233

2 Imperiale TF, Chalasani N. A meta-analysis of endoscopic variceal ligation for primary prophylaxis of esophageal variceal bleeding. Hepatology 2001; 33: 802-807

3 Van Vlierberghe H, De Vos M, Hautekeete M et al. Severe bleeding following endoscopic variceal ligation: should EVL be avoided in Child C patients? Acta Gastroenterol Belg 1999; 62: 175-177

4 Mishin I, Dolghii A. Early spontaneous slippage of rubber bands with fatal bleeding: a rare complication of endoscopic variceal ligation. Endoscopy 2005; 37: 275-276

5 Vanbiervliet G, Giudicelli-Bornard S, Piche T et al. Predictive factors of bleeding related to post-banding ulcer following endoscopic variceal ligation in cirrhotic patients: a case-control study. Aliment Pharmacol Ther 2010; 32: 225-232

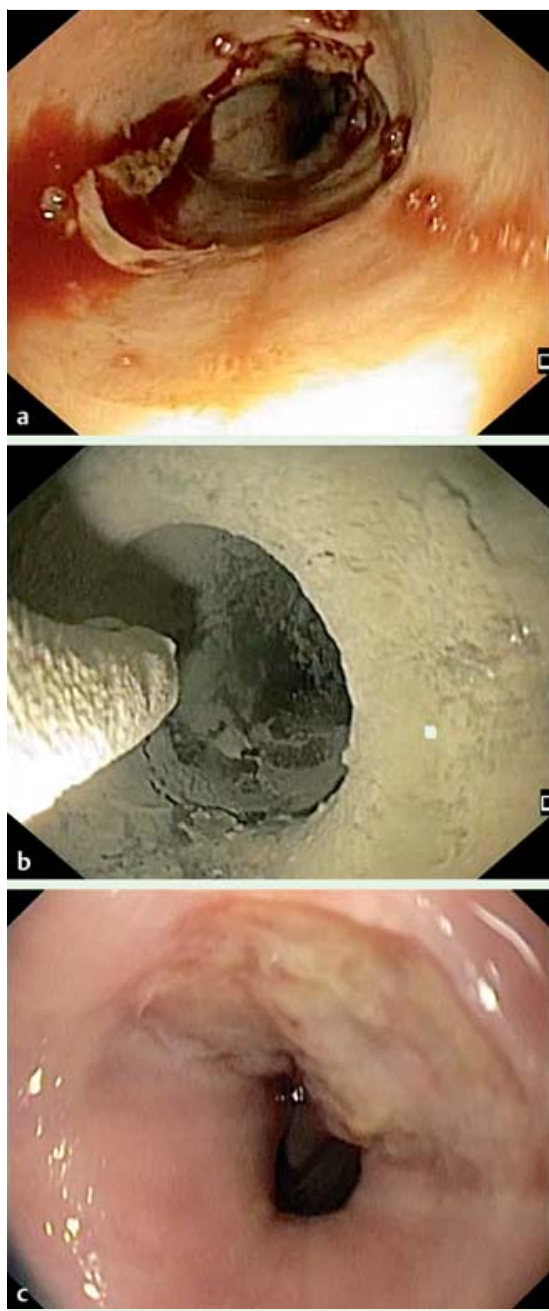

Fig. 1 a Actively bleeding ulcer following esophageal variceal band ligation (EVL). b Application of hemostatic powder. c Appearance at 24-hour follow-up endoscopy.

Bibliography

Dol http://dx.doi.org/

$10.1055 / \mathrm{s}-0034-1365112$

Endoscopy 2014; 46: E263

(c) Georg Thieme Verlag KG

Stuttgart · New York

ISSN 0013-726X

\section{Corresponding author}

\section{Mostafa Ibrahim, MD}

Department of Gastroenterology

Erasme Hospital

Université Libre de Bruxelles

Brussels, Belgium

Fax: +32-2-0106107100

mostafa.ibrahim@webgit.net 